\title{
Regulation of intestinal stem cell fate specification
}

\author{
QI Zhen \& CHEN Ye-Guang* \\ State Key Laboratory of Biomembrane and Membrane Biotechnology, Tsinghua-Peking Center for Life Sciences, School of Life Sciences, \\ Tsinghua University, Beijing 100084, China
}

Received August 19, 2014; accepted September 17, 2014; published online May 6, 2015

\begin{abstract}
The remarkable ability of rapid self-renewal makes the intestinal epithelium an ideal model for the study of adult stem cells. The intestinal epithelium is organized into villus and crypt, and a group of intestinal stem cells located at the base of crypt are responsible for this constant self-renewal throughout the life. Identification of the intestinal stem cell marker Lgr5, isolation and in vitro culture of Lgr5+ intestinal stem cells and the use of transgenic mouse models have significantly facilitated the studies of intestinal stem cell homeostasis and differentiation, therefore greatly expanding our knowledge of the regulatory mechanisms underlying the intestinal stem cell fate determination. In this review, we summarize the current understanding of how signals of Wnt, BMP, Notch and EGF in the stem cell niche modulate the intestinal stem cell fate.
\end{abstract}

intestinal stem cells, Wnt, BMP, Notch, EGF, fate specification

Citation: Qi Z, Chen YG. Regulation of intestinal stem cell fate specification. Sci China Life Sci, 2015, 58: 570-578, doi: 10.1007/s11427-015-4859-7

The primary functions of the intestinal tract are to digest food, absorb nutrients and defend infection from bacterial pathogens. To fullfil these functions, the intestinal epithelium has become the most rapidly self-renewing organ in adult mammalian [1], with a $4-5$ day turnover rate [2]. This remarkable constant self-renewing is fueled by a group of special adult stem cells - intestinal stem cells in the crypts.

\section{Intestinal stem cell and its markers}

The intestinal epithelium is composed of numerous repetitive self-renewing crypt-villus units (Figure 1) [3], in which each villus is surrounded by several invaginations - crypts of Lieberkühn. The crypt harboring stem cells and early progenitors is considered as the proliferation compartment, while the differentiation compartment is mainly referred to as the villus composed of multiple differentiated lineages. At the base of each crypt, multiple intestinal stem cells pos-

*Corresponding author (email: ygchen@tsinghua.edu.cn) sess the ability of indefinitely self-renewing while generating early progenitors-transit amplifying (TA) cells [4]. These TA cells divide rapidly and migrate upwards while gradually differentiating into one of the absorptive (enterocytes) or secretory cell lineages (Paneth cells, goblet cells and enteroendocrine cells). Whereas enterocytes, goblet cells and enteroendocrine cells keep moving upwards towards villi tips where they are ejected into the gut lumen via apoptosis, Paneth cells migrate downwards and reside at the bottom of crypts $[5,6]$.

Over the past 40 years, two theories about the identity of intestinal stem cells in crypts have been proposed. The "stem cell zone" model was originally proposed by Leblond and colleagues in $1974[7,8]$, while the "+4 stem cell" model was reported later by Potten and colleagues in 1978 [9]. In the "stem cell zone" model, Leblond and colleagues proposed the crypt base columnar cells (CBC) wedged between Paneth cells are intestinal stem cells, and these CBC cells establish a stem cell permissive zone together with Paneth cells at the bottom of crypt. Once exiting this zone, their daughter cells gradually commit to multiple 


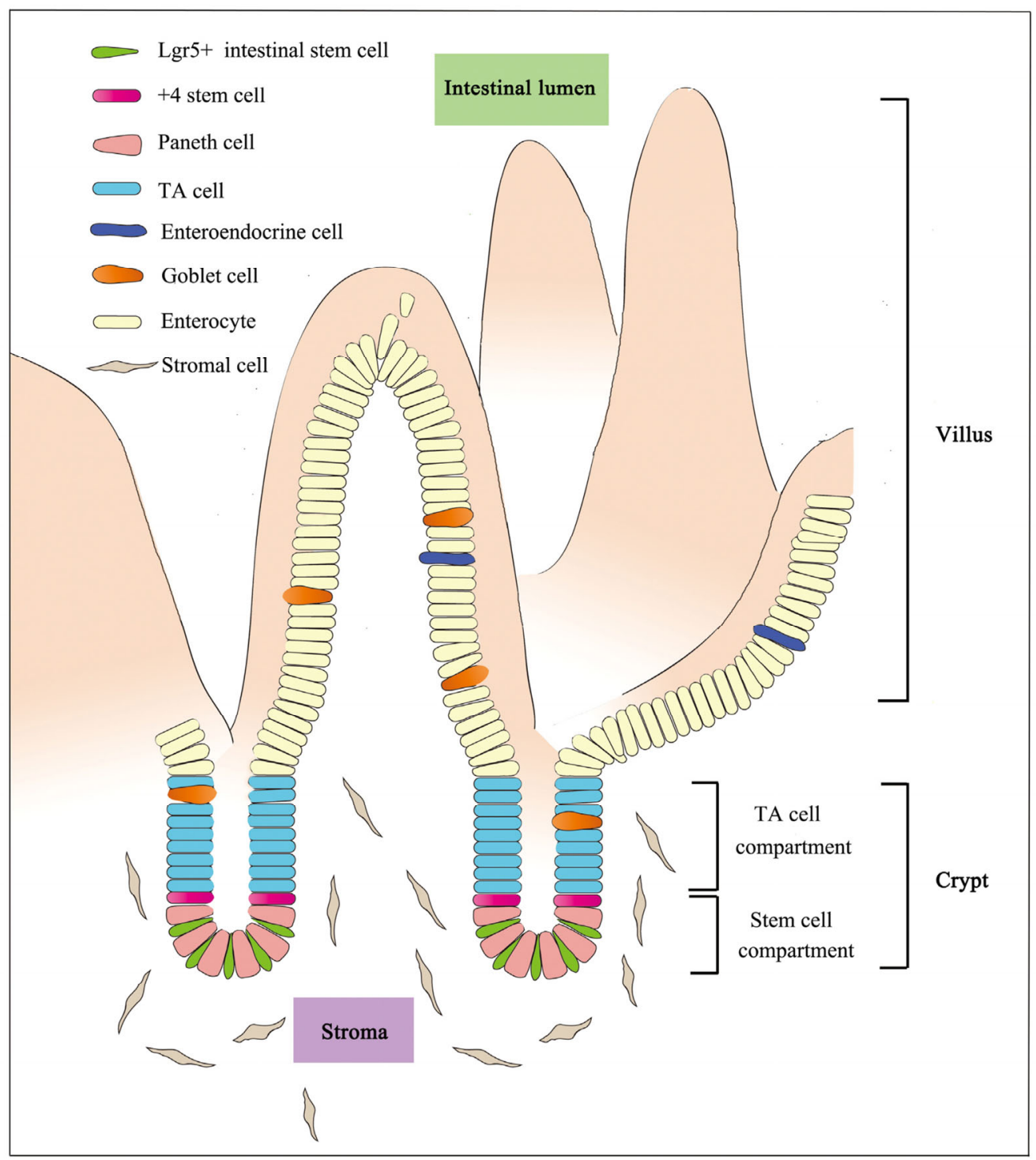

Figure 1 The intestinal epithelium and stem cells. The intestinal epithelium is divided into protruding villi and invaginating crypts. Lgr5+ intestinal stem cells at the base of crypt are wedged between Paneth cells, and " +4 stem cells" reside right above the Paneth cells. Adjacent epithelial cells, pericryptal stromal cells and the basement membrane constitute the stem cell niche, in which stem cells maintain the ability of self-renewing while generating TA cells. These TA cells divide rapidly and migrate upwards while gradually differentiating into one of the absorptive or secretory cell lineages. The enterocytes, goblet cells and enteroendocrine cells keep moving upwards towards villi tips where they are eventually ejected into the gut lumen via apoptosis. On the contrary, Paneth cells migrate downwards towards the bottom of crypts.

differentiated lineages [10,11]. On the other hand, however, the " +4 stem cell" model suggestes that intestinal stem cells reside at position 4 right above the Paneth cells. These +4 stem cells are capable of retaining labelled DNA, which is well consistent with the "immortal strand hypothesis" described in the adult stem cells by John Cairns and colleagues in 1975 [12]. More specifically, the "immortal strand" is achieved through asymmetic segregation of the old DNA strands and newly synthesized DNA strands into stem cell and its progeny respectively during mitosis. However, due to the lack of specific markers for these proposed stem cells, the debate has never stopped until the first specific intestinal stem cell maker Lgr5 (leucine-rich repeat-containing G-protein-coupled receptor 5) was identified in 2007. Thereafter, this field has been experiencing an accelerated advance.

\subsection{The CBC cells marked by Lgr5}

As Wnt signal is one of the major forces supporting the crypt proliferation [13], Wnt target genes might indicate the location of intestinal stem cells in crypts. Hans Clevers and colleagues investigated a Wnt target gene expression profile with microarray on colon cancer cell line LS174T [14] and further revealed that the Wnt target gene Lgr5 is selectively expressed in the CBC cells at the bottom of crypt. The se- 
lective expression of Lgr5 in the CBC cells can be clearly observed in Lgr5-LacZ and $L g r 5^{\text {EGFP-ires-CreERT2 }}$ knock-in mouse models established later [15]. Then, a lineage tracing experiment in $L g r 5^{\text {EGFP-ires-CreERT2 }} / R 26 R$-LacZ mice identified Lgr5 to be a reliable marker for intestinal stem cells. Through activation of LacZ expression in a single Lgr5+ cell by low-dose-tamoxifen-induced Cre recombination, all of its daughter cells could express LacZ continuously. These Lgr5+ cells-derived cells expanded from the crypt to the villus in a short period and differentiated to all of the four cell lineages [15]. Consistently, a single Lgr5+ CBC cell can grow into long-term organoid in vitro with the ability of self-renewal and differentiation [16]. These pieces of evidence together validate that Lgr5+ CBC cells indeed represent the intestinal stem cells.

In a follow-up study, analysis of gene expression program in single Lgr5+ intestinal stem cells through FACS (fluorescence-activated cell-sorted) further unveiled other putative stem cell markers. Thus, another Wnt target gene Ascl2 (achaete-scute complex homolog 2) was identified as an exquisite marker for $\mathrm{CBC}$ cells and a master regulator in intestinal stem cells [17]. Besides, Olfm4 (olfactomedin 4) was also reported as a specific intestinal stem cell marker [18]. Until now, it is generally acknowledged that Lgr5+ $\mathrm{CBC}$ cells are the best described intestinal stem cells.

\subsection{The +4 stem cells marked by Bmi1}

Attempts to characterize the " +4 stem cell" originally reported by Potten and colleagues have also been made over the past few decades. Bmil (bmi1 polycomb ring finger oncogene) was the first reported marker for " +4 stem cell", which was validated by lineage tracing experiment [19]. Further study indicated that the Bmil+ stem cells represent a stem cell population that is relatively quiescent and injury-resistant. Upon radiation-induced injury, the Bmi1+ stem cells can rapidly proliferate to compensate the loss of actively cycling Lgr5+ stem cells [20]. Other putative +4 stem cell markers include mTert (telomerase reverse transcriptase) [21], Hopx (hop homeobox) [22] and Lrig1 (leucine-rich repeats and immunoglobulin-like domains 1) [23]. However, it is worth to note that a series of recent studies argued that all these +4 markers exhibit a rather broader expression pattern and are even most abundant in the Lgr5+ CBC cells, which challenges them as " +4 stem cell" markers. The true identity of " +4 stem cell" originally reported by Potten still needs further clarification.

In recent years, researchers in this field have gradually acknowledged a plasticity theory [24]. The theory proposes that the intestinal crypts harbor two pools of stem cells, Lgr5+ CBC cells (actively cycling and responsible for daily renewal) and +4 reserve stem cells (relatively quiescent and responsible for injury-induced regeneration), and that these two pools may interconvert with each other under certain circumstance.

\section{Signals modulating the intestinal stem cell fate}

Although dispute about the true identity of intestinal stem cells still exists, there is a consensus that intestinal stem cells live in a specialized niche, where signals of Wnt, BMP (bone morphogenetic protein), Notch and EGF (epidermal growth factor) work in concert to modulate the intestinal stem cell fate including self-renewal, proliferation and differentiation (Figure 2).

\subsection{The intestinal stem cell niche}

The intestinal stem cells reside in a specialized niche containing adjacent epithelial cells, pericryptal stromal cells and the basement membrane. This stem cell niche supplies essential signals of EGF, Wnt, BMP and Notch to orchestrate the self-renewal, proliferation and differentiation of intestinal stem cells [25]. Recently, the contribution of Paneth cells in the stem cell niche has received intense attention, as each of individual Lgr5+ intestinal stem cells is in close contact with surrounding Paneth cells, which secrete various important niche ligands including EGF, Wnt3a and Notch [26-28].

\subsection{Wnt signals}

The Wnt signals exhibit a spatial gradient along the crypt-villus axis, with the highest activity in proliferating crypt and the lowest activity in differentiating villus [29]. In the intestinal stem cell niche, Wnt ligands are mainly secreted by epithelial cells and pericryptal stromal cells [30,31], among which Paneth cells have been shown to represent a primary source of Wnt3a ligands [27].

The Wnt signaling pathway plays an evolutionarily conserved role in controlling a series of embryonic development processes and in modulating the self-renewal of a number of adult stem cells [32]. In the absence of Wnt ligands, the destruction complex containing Axin2 (axis inhibition 2), APC (adenomatosis polyposis coli), CK1 (casein kinase 1) and GSK-3 $\beta$ (glycogen synthase kinase 3 beta) promotes the proteasomal degradation of cytoplasmic $\beta$-catenin. Once engaging the Frizzled-Lrp5/6 co-receptors, Wnt ligands increase the stabilization of $\beta$-catenin, resulting in the translocation of accumulated $\beta$-catenin into the nucleus where it regulates target gene expression together with the Tcf (T-cell-specific transcription factor) family of transcription factors [33].

In intestine, Wnt signals play a critical role in maintaining the self-renewal and proliferation of intestinal stem cells. Back to early 1990s, it was found that a majority of colorectal cancers have active Wnt signaling, by harboring mutations of the APC gene [34,35], which encodes a key negative regulator of Wnt signaling. In rare cases of APC posi- 


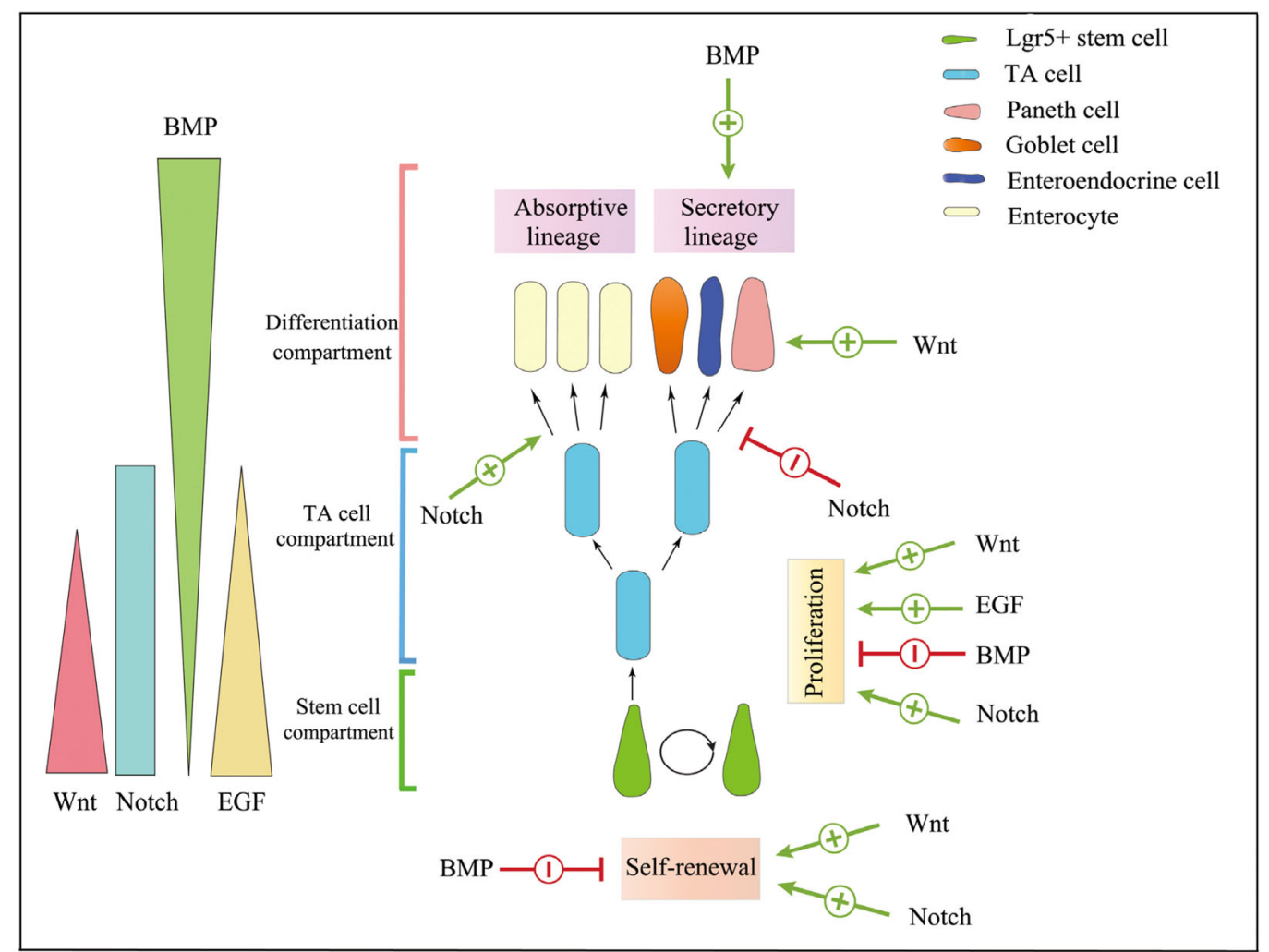

Figure 2 Signals controlling intestinal stem cell fate. Along the crypt-villus axis, Wnt, Notch, BMP and EGF signals exhibit spatial gradients. As an example, the activity of Wnt signaling decreases gradually towards the villus. These four signaling pathways work together to regulate the intestinal stem cell fate including self-renewal, proliferation and differentiation. Firstly, Wnt signals cooperate with Notch signals to maintain the self-renewal of stem cells, while BMP signals restrain the stemness. Secondly, Wnt, EGF and Notch support the stem cell proliferation, whereas BMP signals have opposite effects. Thirdly, Notch functions in directing the specification of absorptive versus secretory lineages, and BMP mainly promotes the maturation of secretory lineages. Lastly, Wnt signaling specifies Paneth cells.

tive colorectal cancers, oncogenic point mutations of $\beta$-catenin, the key downstream effector of Wnt pathway, were frequently detected [36]. The activating mutations of the Wnt/ $\beta$-catenin pathway components suggest the central role of Wnt signaling in the homeostasis of intestinal epithelium. This note was supported by more direct evidence. The Tcf7l2 (encodes TCF4 transcription factor) knockout mice died within $24 \mathrm{~h}$ after birth due to the lack of proliferative stem cell compartments in the small intestine [13,37]. Similarly, intestine-specific ectopic expression of Dkk1 (dickkopf Wnt signaling pathway inhibitor 1), a secreted Wnt antagonist, greatly reduced the number of stem cells and proliferative compartments in the intestine of grown mice [38]. These data indicate that Wnt signals are essential for the postnatal establishment of stem cell compartment in intestine. On the other hand, ample evidence also indicates that the maintenance of the proliferative stem cell compartment in adult mice continuously relies on Wnt signals. Adenoviral expression of Dkk1 [39] or intestine-specific induced-knockout of Ctnnbl (encodes $\beta$-catenin) [40] quickly results in loss of stem cell compartments and impairs daily renewal of epithelium. Consistently, deletion of $c-M y c$, a Wnt target gene, causes rapid disruption of the proliferating crypts [41]. On the contrary, over-activation of Wnt signals can induce augmentation of proliferating stem cell compartments, and eventually intestinal adenomas. Knockout of Apc gene $[42,43]$, intestine-specific overexpression of constitutively active $\beta$-catenin [44] or transgenic expression of R-spondin [45], a secreted Wnt agonist, readily drive hyperplasia in intestine and colon. Rnf43 (ring finger protein 43) and Znrf3 (zinc and ring finger 3) are two related Wnt target genes in intestine and encode transmembrane E3 ligases that induce endocytosis and degradation of Frizzled receptors on the membrane [46]. Simultaneous deletion of these two genes in intestine rapidly causes growing adenomas with enlarged stem cell compartments and increased number of Ki67+ proliferating cells [47]. These data together suggest that Wnt signaling plays a crucial role in the maintenance of intestinal stem cells, and its activity is under a tight control of multiplexed mechanisms - over-activation leads to hyperplasia.

Wnt signals can also promote the maintenance of intestinal stem cells by regulating the EphB-Ephrin B signaling gradient along the crypt-villus axis to form different compartments in intestinal epithelium [48]. Wnt target gene EphB2 and EphB3 encode membrane receptors for mem- 
brane-bound Ephrin B ligands and exhibit the highest expression in the intestinal stem cell compartment with high Wnt activity. Upon entering the TA cell compartment with lower Wnt activity, the progeny of stem cells gradually lose the expression of EphB2 and EphB3 and start to express Ephrin B ligands, resulting in the complementary distribution of EphB and Ephrin B along the crypt-villus axis. EphB receptors and Ephrin ligands are best known for their roles in mediating cell repulsion. When cells expressing EphB receptors and Ephrin ligands come into contact, the EphB-Ephrin B complex can induce bidirectional signals: forward signals that activate downstream signaling cascades including R-Ras to regulate cytoskeleton and cell junction in EphB cells, and reverse signals that control cell adhesion through phosphorylation of Ephrin B by Src family kinases in Ephrin B cells. Clearance of the EphB-Ephrin B complexes at contact sites is crucial for the initiation of repulsion response, which is mediated via endocytosis of the cell surface EphB-Ephrin B complex or protease-mediated cleavage of the extracellular domain of Ephrin B ligands [49-51]. As a consequence, the cells expressing Ephrin B are pushed away from the crypt bottom, while intestinal stem cells are restricted in the stem cell compartment. Of note, the absence of Ephrin B ligands and the high expression of EphB3 receptor in mature Paneth cells allow these cells to migrate to the bottom of the crypts. Thus, Wnt signals can promote the maintenance of intestinal stem cells through controlling the EphB-Ephrin B gradient.

Wnt signals in the intestine not only control the maintenance of the stem cell compartment, but also are crucial for the lineage specification of stem cells, especially the differentiation of Paneth cells. On the one hand, activation of Wnt signaling drives the formation of massive ectopic Paneth cells [31,52]. On the other hand, Wnt target gene Sox9 is required for Paneth cell differentiation, as Sox9 inactivation in intestinal epithelium completely eliminates the Paneth cell lineage in crypts [26]. These data suggest that active Wnt signaling can induce the formation of Paneth cell lineage, which in turn provides the main source of Wnt3a ligands in the stem cell niche [27]. Thus, the Wnt dependent positive-feedback loop in the crypts plays an essential role in stem cell maintenance. Recent studies also suggest the function of Wnt signaling in the differentiation of other secretory cell lineages, goblet cells and enteroendocrine cells $[38,43,53]$.

\subsection{BMP signals}

In contrary to Wnt signals, the activity of BMP signals is gradually elevated towards the villus compartment. Expression of BMP ligands is mainly detected in intravillus and pericryptal mesenchyme [54,55], whereas BMP antagonists Noggin and Chordin are highly produced by the submucosal region adjacent to the crypt bottom [56].

BMPs belong to the transforming growth factor beta
(TGF $\beta$ ) superfamily, and play essential roles during embryonic development and adult stem cell homeostasis through modulating cell proliferation, differentiation and apoptosis [57,58]. Upon binding to BMP ligands, the type-II receptor BMPRII phosphorylates and activates the type-I receptor BMPRI, which in turn phosphorylates R-Smads including Smad1, Smad5 and Smad8. Phosphorylated R-Smads form a complex with Co-Smad (Smad4) and translocate into the nucleus where they cooperate with other transcription factors to regulate target gene transcription [59].

The BMP signals act as a negative regulator of selfrenewal and proliferation of intestinal stem cells, thereby playing essential roles in preventing the intestinal hyperplasia. Consistently, frequent mutations of BMP components including type-I receptor BMPRIA and SMAD4 were identified in Juvenile polyposis syndrome, an inherited syndrome with a high risk of adenocarcinoma [60,61]. In Noggin transgenic mice, ectopic crypts containing stem cell compartments and proliferating cells could be easily detected in the intestinal epithelium including villus compartments, which eventually resulted in gastrointestinal cancers [54]. Similarly, conditional deletion of Bmprla in mice induced expansion of intestinal stem cell compartments, ultimately leading to intestinal adenomas. It was suggested that BMP signals exert this function through directly suppressing Wnt signaling [62].

The BMP signals have also been reported to play important roles in promoting terminal differentiation of several secretory lineages. Mice lacking Bmprla exclusively in the intestinal epithelium exhibited not only increased proliferation but also impaired maturation of all three secretory lineages including goblet cells, Paneth cells and enteroendocrine cells. BMP signals could be important for the terminal differentiation of several secretory lineages but not fate determination [63].

\subsection{Notch signals}

Notch signaling is highly conserved across the metazoa [64]. In mammals, membrane-bound Notch ligands (Jagged1, Jagged3, Dl11, Dll3 and Dl14) interact with Notch receptors (Notch1, Notch2, Notch3 and Notch4) on adjacent cell, leading to liberation of the Notch intracellular domain (NICD) by $\gamma$-secretase-mediated proteolytic cleavage. Released NCID translocates into the nucleus and modulates target gene expression through binding to Rbpj (recombination signal binding protein for immunoglobulin kappa $\mathbf{J}$ region) transcription factors [65].

In the intestine, several Notch ligands and receptors are specifically expressed in crypt cells, thus limiting the activity of this signaling within the crypt compartment [66]. The Notch signals have been shown to play a major role in controlling differentiation, self-renewal and proliferation of intestinal stem cells. Firstly, Notch signals act as the key 
regulator of secretory versus absorptive fate determination by inhibiting the secretory lineage specification while driving absorptive lineage differentiation. Knockout of Rbpj [67], double deletion of Notch1 and Notch2 [68] or simultaneous inactivation of Dll1 and Dll4 [69] all quickly resulted in the complete conversion of proliferating cells into goblet cells and meanwhile loss of Lgr5+ stem cells. Similar phenotype of secretory cell hyperplasia was also observed in mice administrated with $\gamma$-secretase inhibitor $[67,70]$. Conversely, activation of Notch signaling in intestinal epithelium impaired secretory lineage specification while amplifying the proliferative compartment [71,72]. These fate decisions are achieved through the Notch downstream cascade: activation of Notch signaling induces the expression of transcription factor Hes1 (hairy and enhancer of split 1) [73-75], which in turn represses transcription of Math1, a transcription factor required for the commitment into the secretory lineage $[76,77]$. Thus Notch signaling inhibits the commitment of stem cells toward the secretory lineage and allows stem cells to proliferate and further differentiate to the enterocyte lineage [67]. Notch signaling is also essential for the maintenance of proliferation and self-renewal of intestinal stem cells. DIl1 and Dll4 are actively expressed in Paneth cells in the stem cell niche [16]. Moreover, intestinal stem cell-specific marker Olfm4 is under direct transcriptional control of Notch signaling [78]. In summary, Notch signaling protects the Lgr5 stem cells from differentiation into the secretory lineage while cooperating with Wnt signaling to maintain the stemness of stem cells with high Wnt activity, and directs absorptive versus secretory lineage fate specification in TA cell compartment with low Wnt activity [79].

\subsection{EGF signals}

The EGF receptors comprise four members of the ErbB family of receptor tyrosine kinase (EGFR, ErbB-2, ErbB-3 and ErbB-4) that can be activated by EGF-like growth factors to regulate cell proliferation and differentiation through a series of downstream signaling cascades (PI3K/Akt, Ras/Raf/Mek/Erk and/or PLC $\gamma /$ PKC pathways) [80,81].

In intestine, EGF signals provide strong supports for the proliferation and survival of stem cells and TA cells $[82,83]$. Consistent with this, the EGF downstream signaling cascade Ras/Raf/Mek/Erk is active in the crypts [84]. It is worth noting that a strict negative-feedback loop also exists in the stem cell compartment to control an appropriate level of mitogenic EGF signaling. For example, intestine-specific inactivation of Lrig 1, an ErbB negative regulator that is normally expressed in stem cell and progenitor compartment, resulted in duodenal adenomas with amplified stem cell compartment, indicating that the ErbB negative regulator Lrig1 acts as a tumor suppressor in the intestine $[84,23]$.

\subsection{In vitro culture of intestinal stem cell assisted by growth factors}

Previous studies on intestinal stem cells mainly rely on transgenic mouse models. Although this genetic approach has provided ample and clear information, it is also time-consuming and laborious with limits on mechanistic insights. Recently, the identification of Lgr5+ intestinal stem cells and the advances in niche research have made it possible to establish in vitro models for mechanistic studies. In 2009, Hans Clevers and colleagues successfully established an in vitro three-dimensional culture system, in which single Lgr5+ stem cells can grow into intestinal organoids in Matrigel supplemented with certain growth factors including R-spondin-1, EGF, Noggin and Notch ligands [16]. The intestinal organoids retain many key features of the in vivo intestinal epithelium, such as the architecture, cell type composition and basic characteristics of stem cells (self-renewal and differentiation). R-spondin-1 is thought to act as a Wnt agonist to amplify Wnt signaling via engaging Lgr5/4 receptors $[85,86]$. The establishment of this in vitro culture system further demonstrates the critical roles of the four signals in stem cell maintenance and fate determination.

\section{Summary and perspectives}

The ability of rapid self-renewal and the simple physical architecture have made the intestinal epithelium become an ideal model system in adult stem cell research. More importantly, the recent characterization of Lgr5+ stem cells made it possible to make a deep investigation on the stem cells.

Signals of Wnt, BMP, Notch and EGF exert tight controls on the fate determination of intestinal stem cells in its niche. In the stem cell compartment, Wnt signals cooperate with Notch signals to maintain the self-renewal of stem cells, while BMP signals restrain the stemness. In the stem cell compartment and TA cell compartment, Wnt signals, Notch signals and EGF signals work in concert to support the proliferation, while BMP signals represent the counterforce that fights against the intestinal hyperplasia. In the TA cell compartment, Notch signals play a critical role in specifying absorptive versus secretory lineage, and BMP signals mainly promote the terminal differentiation of secretory cells. Also, Wnt signaling is essential for the differentiation of Paneth cells, which are crucial for the establishment of stem cell niche. In summary, intestinal homeostasis is tightly controlled by a complicated signaling network in the niche, and disfunction of this network results in gut carcinogenesis or other types of disorders.

Until now, despite recent great advancements in our understanding of the regulatory mechanisms underlying self-renewal and fate specification of intestinal stem cells, 
there are still many questions to be resolved. For instance, the identity of " +4 stem cells" is still unclear. How do the "+4 stem cells" respond to the signals in the niche? How do multiple signals coordinate to control the fate determination of stem cells? It is certain that our increasing knowledge about the signaling network of maintaining intestinal homeostasis can not only provide important insights into the study of other adult stem cells, but also have outstanding implications in gut disease treatment and stem cell-based regenerative medicine.

This work was supported by the National Natural Science Foundation of China $(31330049,31221064)$ and National Basic Research Program of China (2011CB943803, 2011CBA01104, 2010CB833706) to Chen Ye-Guang.

1 Heath JP. Epithelial cell migration in the intestine. Cell Biol Int, 1996, 20: 139-146

2 Potten CS. Kinetics and possible regulation of crypt cell populations under normal and stress conditions. Bull Cancer, 1975, 62: 419-430

3 Barker N, van de Wetering $\mathrm{M}$, Clevers $\mathrm{H}$. The intestinal stem cell. Genes Dev, 2008, 22: 1856-1864

4 Hermiston ML, Gordon JI. Organization of the crypt-villus axis and evolution of its stem cell hierarchy during intestinal development. Am J Physiol, 1995, 268: G813-822

5 van der Flier LG, Clevers H. Stem cells, self-renewal, and differentiation in the intestinal epithelium. Annu Rev Physiol, 2009, 71: $241-260$

6 Hall PA, Coates PJ, Ansari B, Hopwood D. Regulation of cell number in the mammalian gastrointestinal tract: the importance of apoptosis. J Cell Sci, 1994, 107: 3569-3577

7 Cheng H, Leblond CP. Origin, differentiation and renewal of the four main epithelial cell types in the mouse small intestine. V. Unitarian Theory of the origin of the four epithelial cell types. Am J Anat, 1974, 141: 537-561

8 Cheng H, Leblond CP. Origin, differentiation and renewal of the four main epithelial cell types in the mouse small intestine. I. Columnar cell. Am J Anat, 1974, 141: 461-479

9 Potten CS, Hume WJ, Reid P, Cairns J. The segregation of DNA in epithelial stem cells. Cell, 1978, 15: 899-906

10 Bjerknes $\mathrm{M}$, Cheng $\mathrm{H}$. The stem-cell zone of the small intestinal epithelium. III. Evidence from columnar, enteroendocrine, and mucous cells in the adult mouse. Am J Anat, 1981, 160: 77-91

11 Bjerknes $\mathrm{M}$, Cheng $\mathrm{H}$. The stem-cell zone of the small intestinal epithelium. I. Evidence from Paneth cells in the adult mouse. Am J Anat, 1981, 160: 51-63

12 Cairns J. Mutation selection and the natural history of cancer. Nature, 1975, 255: 197-200

13 Korinek V, Barker N, Moerer P, van Donselaar E, Huls G, Peters PJ, Clevers H. Depletion of epithelial stem-cell compartments in the small intestine of mice lacking Tcf-4. Nat Genet, 1998, 19: 379-383

14 van de Wetering M, Sancho E, Verweij C, de Lau W, Oving I, Hurlstone A, van der Horn K, Batlle E, Coudreuse D, Haramis AP, Tjon-Pon-Fong M, Moerer P, van den Born M, Soete G, Pals S, Eilers M, Medema R, Clevers H. The beta-catenin/TCF-4 complex imposes a crypt progenitor phenotype on colorectal cancer cells. Cell, 2002, 111: 241-250

15 Barker N, van Es JH, Kuipers J, Kujala P, van den Born M, Cozijnsen M, Haegebarth A, Korving J, Begthel H, Peters PJ, Clevers $\mathrm{H}$. Identification of stem cells in small intestine and colon by marker gene Lgr5. Nature, 2007, 449: 1003-1007

16 Sato T, Vries RG, Snippert HJ, van de Wetering M, Barker N, Stange DE, van Es JH, Abo A, Kujala P, Peters PJ, Clevers H. Single Lgr5 stem cells build crypt-villus structures in vitro without a mesenchymal niche. Nature, 2009, 459: 262-265
17 van der Flier LG, van Gijn ME, Hatzis P, Kujala P, Haegebarth A, Stange DE, Begthel H, van den Born M, Guryev V, Oving I, van Es $\mathrm{JH}$, Barker N, Peters PJ, van de Wetering $\mathrm{M}$, Clevers $\mathrm{H}$. Transcription factor achaete scute-like 2 controls intestinal stem cell fate. Cell, 2009, 136: 903-912

18 van der Flier LG, Haegebarth A, Stange DE, van de Wetering M, Clevers H. OLFM4 is a robust marker for stem cells in human intestine and marks a subset of colorectal cancer cells. Gastroenterology, 2009, 137: 15-17

19 Tian H, Biehs B, Warming S, Leong KG, Rangell L, Klein OD, de Sauvage FJ. A reserve stem cell population in small intestine renders Lgr5-positive cells dispensable. Nature, 2011, 478: 255-259

20 Yan KS, Chia LA, Li X, Ootani A, Su J, Lee JY, Su N, Luo Y, Heilshorn SC, Amieva MR, Sangiorgi E, Capecchi MR, Kuo CJ. The intestinal stem cell markers Bmil and Lgr5 identify two functionally distinct populations. Proc Natl Acad Sci USA, 2012, 109: 466-471

21 Montgomery RK, Carlone DL, Richmond CA, Farilla L, Kranendonk ME, Henderson DE, Baffour-Awuah NY, Ambruzs DM, Fogli LK, Algra S, Breault DT. Mouse telomerase reverse transcriptase (mTert) expression marks slowly cycling intestinal stem cells. Proc Natl Acad Sci USA, 2011, 108: 179-184

22 Takeda N, Jain R, LeBoeuf MR, Wang Q, Lu MM, Epstein JA. Interconversion between intestinal stem cell populations in distinct niches. Science, 2011, 334: 1420-1424

23 Powell AE, Wang Y, Li Y, Poulin EJ, Means AL, Washington MK, Higginbotham JN, Juchheim A, Prasad N, Levy SE, Guo Y, Shyr Y, Aronow BJ, Haigis KM, Franklin JL, Coffey RJ. The pan-ErbB negative regulator Lrig1 is an intestinal stem cell marker that functions as a tumor suppressor. Cell, 2012, 149: 146-158

24 Clevers $\mathrm{H}$. The intestinal crypt, a prototype stem cell compartment. Cell, 2013, 154: 274-284

25 Barker N. Adult intestinal stem cells: critical drivers of epithelial homeostasis and regeneration. Nat Rev Mol Cell Biol, 2014, 15: 19-33

26 Bastide P, Darido C, Pannequiri J, Kist R, Robine S, Marty-Double C, Bibeau F, Scherer G, Joubert D, Hollande F, Blache P, Jay P. Sox9 regulates cell proliferation and is required for Paneth cell differentiation in the intestinal epithelium. J Cell Biol, 2007, 178: 635-648

27 Sato T, van Es JH, Snippert HJ, Stange DE, Vries RG, van den Born M, Barker N, Shroyer NF, van de Wetering M, Clevers H. Paneth cells constitute the niche for Lgr5 stem cells in intestinal crypts. Nature, 2011, 469: 415-418

28 Geiser J, Venken KJT, De Lisle RC, Andrews GK. A mouse model of acrodermatitis enteropathica: loss of intestine zinc transporter ZIP4 (Slc39a4) disrupts the stem cell niche and intestine integrity. PLoS Genet, 2012, 8: e1002766

29 Vries RGJ, Huch M, Clevers H. Stem cells and cancer of the stomach and intestine. Mol Oncol, 2010, 4: 373-384

30 Gregorieff A, Pinto D, Begthel H, Destree O, Kielman M, Clevers H. Expression pattern of Wnt signaling components in the adult intestine. Gastroenterology, 2005, 129: 626-638

31 Farin HF, Van Es JH, Clevers H. Redundant sources of Wnt regulate intestinal stem cells and promote formation of paneth cells. Gastroenterology, 2012, 143: 1518-1529

32 Logan CY, Nusse R. The Wnt signaling pathway in development and disease. Annu Rev Cell Dev Biol, 2004, 20: 781-810

33 Clevers $\mathrm{H}$. Wnt/beta-catenin signaling in development and disease. Cell, 2006, 127: 469-480

34 Groden J, Thliveris A, Samowitz W, Carlson M, Gelbert L, Albertsen H, Joslyn G, Stevens J, Spirio L, Robertson M. Identification and characterization of the familial adenomatous polyposis coli gene. Cell, 1991, 66: 589-600

35 Kinzler KW, Nilbert MC, Su LK, Vogelstein B, Bryan TM, Levy DB, Smith KJ, Preisinger AC, Hedge P, McKechnie D. Identification of FAP locus genes from chromosome 5q21. Science, 1991, 253: 661-665

36 Morin PJ, Sparks AB, Korinek V, Barker N, Clevers H, Vogelstein B, Kinzler KW. Activation of beta-catenin-Tcf signaling in colon cancer 
by mutations in beta-catenin or APC. Science, 1997, 275: 1787-1790

37 van Es JH, Haegebarth A, Kujala P, Itzkovitz S, Koo BK, Boj SF, Korving J, van den Born M, van Oudenaarden A, Robine S, Clevers, H. A critical role for the Wnt effector Tcf4 in adult intestinal homeostatic self-renewal. Mol Cell Biol, 2012, 32: 1918-1927

38 Pinto D, Gregorieff A, Begthel H, Clevers, H. Canonical Wnt signals are essential for homeostasis of the intestinal epithelium. Genes Dev, 2003, 17: 1709-1713

39 Kuhnert F, Davis CR, Wang HT, Chu P, Lee M, Yuan J, Nusse R, Kuo CJ. Essential requirement for Wnt signaling in proliferation of adult small intestine and colon revealed by adenoviral expression of Dickkopf-1. Proc Natl Acad Sci USA, 2004, 101: 266-271

40 Fevr T, Robine S, Louvard D, Huelsken J. Wnt/beta-Catenin is essential for intestinal homeostasis and maintenance of intestinal stem cells. Mol Cell Biol, 2007, 27: 7551-7559

41 Muncan V, Sansom OJ, Tertoolen L, Phesse TJ, Begthel H, Sancho E, Cole AM, Gregorieff A, de Alboran IM, Clevers H, Clarke AR. Rapid loss of intestinal crypts upon conditional deletion of the Wnt/Tcf-4 target gene c-Myc. Mol Cell Biol, 2006, 26: 8418-8426

42 Oshima M, Oshima H, Kitagawa K, Kobayashi M, Itakura C, Taketo M. Loss of apc heterozygosity and abnormal tissue building in nascent intestinal polyps in mice carrying a truncated Apc gene. Proc Natl Acad Sci USA, 1995, 92: 4482-4486

43 Sansom OJ, Reed KR, Hayes AJ, Ireland H, Brinkmann H, Newton IP, Batlle E, Simon-Assmann P, Clevers H, Nathke IS, Clarke AR, Winton DJ. Loss of Apc in vivo immediately perturbs Wnt signaling, differentiation, and migration. Genes Dev, 2004, 18: 1385-1390

44 Harada N, Tamai Y, Ishikawa T, Sauer B, Takaku K, Oshima M, Taketo, MM. Intestinal polyposis in mice with a dominant stable mutation of the beta-catenin gene. EMBO J, 1999, 18: 5931-5942

45 Kim KA, Kakitani M, Zhao JS, Oshima T, Tang T, Binnerts M, Liu Y, Boyle B, Park E, Emtage P, Funk WD, Tomizuka K. Mitogenic influence of human R-spondin1 on the intestinal epithelium. Science, 2005, 309: 1256-1259

46 Hao HX, Xie Y, Zhang Y, Charlat O, Oster E, Avello M, Lei H, Mickanin C, Liu D, Ruffner H, Mao, XH Ma QC, Zamponi R, Bouwmeester T, Finan PM, Kirschner MW, Porter JA, Serluca FC, Cong F. ZNRF3 promotes Wnt receptor turnover in an R-spondin-sensitive manner. Nature, 2012, 485: 195-200

47 Koo BK, Spit M, Jordens I, Low TY, Stange DE, van de Wetering M, van Es JH, Mohammed S, Heck AJR, Maurice MM, Clevers H. Tumour suppressor RNF43 is a stem-cell E3 ligase that induces endocytosis of Wnt receptors. Nature, 2012, 488: 665-669

48 Batlle E, Henderson JT, Beghtel H, van den Born MM, Sancho E, Huls G, Meeldijk J, Robertson J, van de Wetering M, Pawson T, Clevers $\mathrm{H}$. Beta-catenin and TCF mediate cell positioning in the intestinal epithelium by controlling the expression of EphB/ephrinB. Cell, 2002, 111: 251-263

49 Pasquale EB. Eph receptors and ephrins in cancer: bidirectional signalling and beyond. Nat Rev Cancer, 2010, 10: 165-180

50 Wilkinson DG. Multiple roles of EPH receptors and ephrins in neural development. Nature reviews. Neuroscience, 2001, 2: 155-164

51 Noren NK, Pasquale EB. Eph receptor-ephrin bidirectional signals that target Ras and Rho proteins. Cell Signal, 2004, 16: 655-666

52 Andreu P, Peignon G, Slomianny C, Taketo MM, Colnot S, Robine S, Lamarque D, Laurent-Puig P, Perret C, Romagnolo B. A genetic study of the role of the Wnt/beta-catenin signalling in Paneth cell differentiation. Dev Biol, 2008, 324: 288-296

53 Nakamura T, Tsuchiya K,Watanabe M. Crosstalk between Wnt and Notch signaling in intestinal epithelial cell fate decision. $J$ Gastroenterol, 2007, 42: 705-710

54 Haramis AP, Begthel H, van den Born M, van Es J, Jonkheer S, Offerhaus GJ, Clevers H. De novo crypt formation and juvenile polyposis on BMP inhibition in mouse intestine. Science, 2004, 303: 1684-1686

55 Hardwick JCH, Van den Brink GR, Bleuming SA, Ballester I, Van den Brande JMH, Keller JJ, Offerhaus GJA, Van Deventer SJH, Peppelenbosch MP. Bone morphogenetic protein 2 is expressed by, and acts upon, mature epithelial cells in the colon. Gastroenterology,
2004, 126: 111-121

56 Kosinski C, Li VS, Chan AS, Zhang J, Ho C, Tsui WY, Chan TL, Mifflin RC, Powell DW, Yuen ST, Leung SY, Chen X. Gene expression patterns of human colon tops and basal crypts and BMP antagonists as intestinal stem cell niche factors. Proc Natl Acad Sci USA, 2007, 104: 15418-15423

57 Massague J. TGF-beta signal transduction. Annu Rev Biochem, 1998, 67: 753-791

58 Zhang J, Li L. BMP signaling and stem cell regulation. Dev Biol, 2005, 284: 1-11

59 Hardwick JC, Kodach LL, Offerhaus GJ, van den Brink GR. Bone morphogenetic protein signalling in colorectal cancer. Nat Rev Cancer, 2008, 8: 806-812

60 Howe JR, Bair JL, Sayed MG, Anderson ME, Mitros FA, Petersen GM, Velculescu VE, Traverso G, Vogelstein, B. Germline mutations of the gene encoding bone morphogenetic protein receptor $1 \mathrm{~A}$ in juvenile polyposis. Nat Genet, 2001, 28: 184-187

61 Howe JR, Roth S, Ringold JC, Summers RW, Jarvinen HJ, Sistonen P, Tomlinson IPM, Houlston RS, Bevan S, Mitros FA, Stone EM, Aaltonen LA. Mutations in the SMAD4/DPC4 gene in juvenile polyposis. Science, 1998, 280: 1086-1088

62 He XC, Zhang JW, Tong WG, Tawfik O, Ross J, Scoville DH, Tian Q, Zeng X, He X, Wiedemann LM, Mishina Y, Li LH. BMP signaling inhibits intestinal stem cell self-renewal through suppression of Wnt-beta-catenin signaling. Nat Genet, 2004, 36: 1117-1121

63 Auclair BA, Benoit YD, Rivard N, Mishina Y, Perreault N. Bone morphogenetic protein signaling is essential for terminal differentiation of the intestinal secretory cell lineage. Gastroenterology, 2007, 133: 887-896

64 Artavanis-Tsakonas S, Rand MD, Lake RJ. Notch signaling: cell fate control and signal integration in development. Science, 1999, 284: 770-776

65 Kopan R, Ilagan M XG. The canonical Notch signaling pathway: unfolding the activation mechanism. Cell, 2009, 137: 216-233

66 Schroder N, Gossler A. Expression of Notch pathway components in fetal and adult mouse small intestine. Gene Expr Patterns, 2002, 2: $247-250$

67 van Es JH, van Gijn ME, Riccio O, van den Born M, Vooijs M, Begthel H, Cozijnsen M, Robine S, Winton DJ, Radtke F, Clevers H. Notch/gamma-secretase inhibition turns proliferative cells in intestinal crypts and adenomas into goblet cells. Nature, 2005, 435: 959-963

68 Riccio O, van Gijn ME, Bezdek AC, Pellegrinet L, van Es JH, Zimber-Strobl U, Strobl LJ, Honjo T, Clevers H. Loss of intestinal crypt progenitor cells owing to inactivation of both Notch1 and Notch2 is accompanied by derepression of CDK inhibitors p27Kip1 and p57Kip2. EMBO Rep, 2008, 9: 377-383

69 Pellegrinet L, Rodilla V, Liu Z, Koch U, Espinosa L, Kaestner KH, Kopan R, Lewis J, Radtke F. D111- and Dll4-mediated notch signaling are required for homeostasis of intestinal stem cells. Gastroenterology, 2011, 140: 1230-1240

70 Milano J, McKay J, Dagenais C, Foster-Brown L, Pognan F, Gadient R, Jacobs RT, Zacco A, Greenberg B, Ciaccio, PJ. Modulation of notch processing by gamma-secretase inhibitors causes intestinal goblet cell metaplasia and induction of genes known to specify gut secretory lineage differentiation. Toxicol Sci, 2004, 82: 341-358

71 Fre S, Huyghe M, Mourikis P, Robine S, Louvard D, Artavanis-Tsakonas S. Notch signals control the fate of immature progenitor cells in the intestine. Nature, 2005, 435: 964-968

72 Stanger BZ, Datar R, Murtaugh LC, Melton DA. Direct regulation of intestinal fate by Notch. Proc Natl Acad Sci USA, 2005, 102: 12443-12448

73 Jensen J, Pedersen EE, Galante P, Hald J, Heller RS, Ishibashi M, Kageyama R, Guillemot F, Serup P, Madsen OD. Control of endodermal endocrine development by Hes-1. Nat Genet, 2000, 24 : 36-44

74 Suzuki K, Fukui H, Kayahara T, Sawada M, Seno H, Hiai H, Kageyama R, Okano H, Chiba, T. Hes1-deficient mice show 
precocious differentiation of Paneth cells in the small intestine. Biochem Biophys Res Commun, 2005, 328: 348-352

75 Ueo T, Imayoshi I, Kobayashi T, Ohtsuka T, Seno H, Nakase H, Chiba T, Kageyama R. The role of Hes genes in intestinal development, homeostasis and tumor formation. Development, 2012, 139: 1071-1082

76 Yang Q, Bermingham NA, Finegold MJ, Zoghbi HY. Requirement of Math1 for secretory cell lineage commitment in the mouse intestine. Science, 2001, 294: 2155-2158

77 VanDussen KL, Samuelson LC. Mouse atonal homolog 1 directs intestinal progenitors to secretory cell rather than absorptive cell fate. Dev Biol, 2010, 346: 215-223

78 VanDussen KL, Carulli AJ, Keeley TM, Patel SR, Puthoff BJ, Magness ST, Tran IT, Maillard I, Siebel C, Kolterud A, Grosse AS, Gumucio DL, Ernst SA, Tsai YH, Dempsey PJ, Samuelson LC. Notch signaling modulates proliferation and differentiation of intestinal crypt base columnar stem cells. Development, 2012, 139: 488-497

79 Medema JP, Vermeulen L. Microenvironmental regulation of stem cells in intestinal homeostasis and cancer. Nature, 2011, 474: 318-326

80 De Luca A, Carotenuto A, Rachiglio A, Gallo M, Maiello MR, Aldinucci D, Pinto A, Normanno N. The role of the EGFR signaling in tumor microenvironment. J Cell Physiol, 2008, 214: 559-567

81 Normanno N, De Luca A, Bianco C, Strizzi L, Mancino M, Maiello
MR, Carotenuto A, De Feo G, Caponigro F, Salomon DS. Epidermal growth factor receptor (EGFR) signaling in cancer. Gene, 2006, 366: $2-16$

82 Estivariz CF, Jonal CR, Gu LH, Diaz EE, Wallace TM, Pascal RR, Farrell CL, Ziegler TR. Gut-trophic effects of keratinocyte growth factor in rat small intestine and colon during enteral refeeding. JPEN J Parenter Enteral Nutr, 1998, 22: 259-267

83 Marchbank T, Goodlad RA, Lee CY, Playford RJ. Luminal epidermal growth-factor is trophic to the small-intestine of parenterally fed rats. Clin Sci (Lond), 1995, 89: 117-120

84 Wong VWY, Stange DE, Page ME, Buczacki S, Wabik A, Itami S, van de Wetering M, Poulsom R, Wright NA, Trotter MWB, Watt FM, Winton DJ, Clevers H, Jensen KB. Lrig1 controls intestinal stem-cell homeostasis by negative regulation of ErbB signalling. Nat Cell Biol, 2012, 14: 401-408

85 de Lau W, Barker N, Low TY, Koo BK, Li VSW, Teunissen H, Kujala P, Haegebarth A, Peters, PJ, van de Wetering M, Stange DE, van Es JE, Guardavaccaro D, Schasfoort RBM, Mohri Y, Nishimori K, Mohammed S, Heck AJR, Clevers H. Lgr5 homologues associate with Wnt receptors and mediate R-spondin signalling. Nature, 2011, 476: 293-297

86 Carmon KS, Gong X, Lin QS, Thomas A, Liu QY. R-spondins function as ligands of the orphan receptors LGR4 and LGR5 to regulate Wnt/beta-catenin signaling. Proc Natl Acad Sci USA, 2011, 108: $11452-11457$

Open Access This article is distributed under the terms of the Creative Commons Attribution License which permits any use, distribution, and reproduction in any medium, provided the original author(s) and source are credited. 